\title{
Maternidade e situações estressantes no primeiro ano de vida do bebê $\hat{e}^{1}$
}

\author{
Andrea Rapoport ${ }^{2}$ - Universidade Federal do Rio Grande do Sul, Porto Alegre, Brasil \\ Cesar Augusto Piccinini - Universidade Federal do Rio Grande do Sul, Porto Alegre, Brasil
}

\begin{abstract}
Resumo
O objetivo do presente estudo foi investigar situações estressantes envolvendo a maternidade no primeiro ano de vida do bebê e o apoio social recebido. Participaram do estudo 39 mães adultas, primíparas, que viviam com seus companheiros. As mães foram entrevistadas quando o bebê tinha um ano de vida. Os resultados revelaram a existência de diversas situações estressantes e houve maior solicitação de apoio social durante essas situações, e quando este foi recebido auxiliou as mães tanto do ponto de vista emocional como prático. Os resultados sugerem que apoio social dado à mãe mostra-se fundamental tanto para ela como para a sua relação com o/a filho/a.

Palavras-chave: Maternidade, Estresse, Apoio social.
\end{abstract}

Motherhood and stressful situations in the first year of the baby's life

\begin{abstract}
The aim of the present study was to investigate stressful situations related to the experience of motherhood and social support in the baby's first year of life. Thirty-nine primiparous adult mothers, who lived with their partners, took part in the study. The mothers were interviewed when the baby was a year old. The results show a number of mothers reported stressful situations during baby's first year of life, especially in the first months. There was greater request for social support during these situations, and when this was received, it helped mothers both from an emotional and a practical point of view. The results suggest that social support given to the mother is fundamental both for her and for her relationship with her child.

Keywords: Motherhood, Stress, Social support.
\end{abstract}

O nascimento de um filho é um evento que modifica a vida do casal, especialmente a da mãe, que comumente assume a maior parte das responsabilidades de cuidado do filho/a. Essas mudanças são ainda maiores no caso de mães primíparas. A reação da recém-mãe a essas mudanças é influenciada tanto por fatores individuais como ambientais. Entre eles, um dos mais importantes, que influencia o seu bem-estar, é o apoio que ela recebe daqueles que a rodeiam, principalmente do pai do bebê (Dunkel-Shetter, Sagrestano, Feldman \& Killingsworth, 1996).

A maternidade e a paternidade se constituem em uma nova etapa do ciclo de vida familiar, o que tende a gerar estresse devido à adaptação necessária, em particular, durante os três primeiros meses de vida do bebê, quando as demandas tendem a ficar exacerbadas (Maldonado, 1990). Nesse sentido, pode haver uma maior solicitação de apoio social por parte da mãe durante esse período (Crockenberg, 1981; Crockenberg \& McCluskey, 1986). Já a disponibilidade de apoio social contribui para facilitar a maternidade, principalmente sob condições estressantes,

\footnotetext{
1 Artigo baseado em parte da tese de doutorado de Andrea Rapoport realizada sob a supervisão de Cesar Augusto Piccinini, apresentada no Programa de Pós-Graduação em Psicologia do UFRGS, Porto Alegre.
}

Endereço para correspondência:

deiar@terra.com.br promovendo o desenvolvimento de um apego seguro bebê-mãe, além de afetar diretamente a criança, pelo contato dela com os membros dessa rede de apoio (Crockenberg, 1981). A possibilidade da mãe contar com pessoas que a auxiliem nessa nova fase e, principalmente, nos momentos difíceis, possibilita que esteja mais disponível afetiva e fisicamente para atender de forma adequada às demandas do bebê.

Diversos autores (Brazelton \& Cramer, 1992; Stern, 1997; Winnicott, 1956) propuseram conceitos e teorias para explicar a transição para a maternidade. Por exemplo, Winnicott (1956) se referiu ao conceito de "preocupação materna primária" para explicar o que seria uma maternidade responsiva ou disponibilidade materna logo após o nascimento. Segundo o autor, caracteriza-se por um estado de sensibilidade aumentada da mãe, que permite que ela se identifique com seu bebê para saber o que ele está sentindo. Inicia no final da gravidez e persiste até algumas semanas após o nascimento.

Já Stern (1997) denominou constelação da maternidade a toda essa modificação e reorganização da vida, experimentadas pela mãe após o nascimento do bebê. Dentre os quatro temas destacados pelo autor como presentes na vida da mãe nesses primeiros meses após o nascimento do bebê (vida-crescimento, relacionar-se primário, a reorganização da identidade e matriz de apoio) destacamos aqui apenas o último deles, pela sua relevância ao presente artigo. $\mathrm{O}$ tema da matriz de apoio refere-se à necessidade da mãe de criar, permitir, aceitar e regular uma rede de apoio protetora para que 
possa manter o bebê vivo e promover seu desenvolvimento psíquico-afetivo. Apresentaria duas funções principais: proteger a mãe fisicamente e apoiála em termos psicológicos e educativos para que ela possa dedicar-se ao bebê. Tradicionalmente, segundo Stern, o apoio do marido restringia-se à tarefa de manutenção física da mulher, enquanto uma figura feminina ficava com a tarefa de apoiá-la e instruí-la em relação ao desempenho da função materna. Com a redução da família, em muitas sociedades, verifica-se atualmente a ampliação das funções atribuídas ao pai. De qualquer modo, para Stern, o principal envolvimento psicológico da mãe ainda ocorre com as figuras maternas de sua vida. Esse tema inclui também as representações da mãe sobre como as pessoas que a ajudam a veem como mãe e sobre sentir-se ameaçada de perder o amor do bebê para essa matriz de apoio.

A literatura tem ressaltado o caráter potencialmente conflituoso da experiência da maternidade como um fator de risco para a ocorrência de distúrbios mentais após o nascimento de um bebê (Rowan, Bick \& Bastos, 2007). Nesse contexto de extrema dedicaçaõ da mãe à maternidade e ao bebê, o apoio de outras pessoas, como o pai do bebê, tem um papel relevante.

$\mathrm{O}$ apoio social diz respeito a uma rede de sistemas e de pessoas significativas que proporcionam apoio e reforço ao indivíduo diante das situações de vida (Brito \& Koller, 1999). Simons e Johnson (1996) caracterizam a rede de apoio social como associada a manifestações de carinho e ao encorajamento e assistência provida por familiares, amigos, vizinhos, profissionais, etc. Este pode envolver uma ajuda emocional (expressões de conforto e cuidado), informacional (informações e orientações), ou instrumental (provisão de recursos, serviços e solução de problemas) que alguém recebe de contatos sociais formais ou informais (Dunkel-Shetter e cols., 1996; Pierce e cols., 1996).

Quando a nova mãe é cercada por pessoas que a ajudam e a apoiam, os sentimentos maternos de autoconfiança e realização pessoal tendem a aumentar, assim como a disposição de dar afeto ao bebê (Maldonado, 1990). Espera-se ainda que um cônjuge se estresse menos emocionalmente diante de eventos aversivos quando o outro parceiro é compreensivo, dá conselhos e assistência (Simons \& Johnson, 1996).

Atualmente, nas sociedades mais desenvolvidas, as redes de apoio social se encontram muitas vezes diminuídas em virtude das atividades envolvendo a vida nas cidades grandes, deixando a mulher muitas vezes só para cuidar do bebê (Stern, 1997; Rapoport, 2003). Isso pode afetar a maternidade e o desenvolvimento do próprio bebê, tendo em vista que, especialmente nesse momento do puerpério, a mulher tende a se sentir mais insegura, pelas várias mudanças que ocorrem em sua vida e pelo fato dela deixar de ser o centro de sua própria vida, privilegiando seu bebê (Falceto, 2002). Por outro lado, Zimmermann, Zimmermann, Zimmermann, Tatsch e Santos (2001) referem que, apesar da importância do apoio social, algumas mães preferem assumir as tarefas sozinhas, como se isso as ajudasse a construir alicerces mais sólidos de sua competência como mães.

Há consenso entre os autores que a experiência da maternidade se constitui em um dos ritos de passagem que marcam a vida de uma mulher e esta é influenciada por fatores da própria mãe e sociais afetando a forma como alcança o seu papel de mãe (Catafesta, Venturi, Zagonel \& Marialda, 2007). Além do apoio social, os autores indicam a preparação antecipatória à maternidade envolvendo a área da saúde como fatores que podem influenciar de forma positiva a adaptação à maternidade.

Além dos inúmeros aspectos subjetivos e sociais destacados acima, exigências e mudanças pontuais podem afetar muito a recém-mãe nos primeiros meses de vida do bebê, como, por exemplo, a privação do sono e a adaptação de sua vida ao ritmo do bebê (Peters, 1999), o que pode se constituir em fatores de muito estresse para elas. Segundo o autor, a maioria das mulheres sabe que os bebês mamam geralmente a cada três horas, mas poucas sabem o que significa acordar a cada três horas ou até mais vezes a cada noite. Além disso, com um recém-nascido a mãe acaba não podendo manter o seu próprio ritmo, não pode viver o cotidiano de sua vida anterior, e acaba muitas vezes sem horários para suas atividades e, sobretudo, para descansar. Como enfatiza Peters, o dia da mãe passa a ser ditado pelas necessidades do bebê, cujos pais vivem "para servir o novo príncipe da casa, que é absolutamente o que todo bebê é" (p. 83). Apesar desses sacrifícios, os filhos podem trazer à tona uma grandeza de amor que surpreende, desarma, domina e gratifica, compensando as frustrações e as dificuldades inerentes ao papel materno e paterno.

Considerando as questões expostas acima, é importante que se investiguem os sentimentos e vivências maternos, especialmente os associados às situações estressantes do primeiro ano de vida do bebê. A exposição do lado difícil e estressante da maternidade tem sido muitas vezes negligenciada historicamente em nossa sociedade em decorrência de diversos mitos e estereótipos que tendem a destacar unicamente seu lado bom e bonito. Nem sempre se aceita que a mãe possa ter dificuldades legítimas e possa se sentir sobrecarregada ao ter que cuidar de um recém-nascido. Soma-se a isso a própria melancolia 
pós-parto, baby blues (Miller, 1997), que afeta um número muito grande de mães e que contribui para exacerbar suas dificuldades e sentimentos negativos. Essa melancolia manifesta-se nos 10 primeiros dias pós-parto e tem como características a irritabilidade, depressão, labilidade do humor, choro fácil e indisposição (Miller, 1997; Maldonado, 1990). Na revisão da literatura realizada por Schwengber, Alfaya, Lopes e Piccinini (2003), os autores referem que esse quadro é uma reação normal no puerpério imediato, atingindo mais de $50 \%$ das novas mães, na primeira semana após o parto e tendo, geralmente, remissão espontânea.

Sendo assim, o objetivo deste estudo foi investigar situações estressantes envolvendo a maternidade no primeiro ano de vida do bebê e o apoio social recebido. Isso permitirá que se explicitem algumas das dificuldades maternas ao longo do primeiro ano do bebê, buscando destacar o quanto estas são comuns e esperadas, bem como seu potencial para desencadear sentimentos negativos na mãe, próprios desse período da vida. Entende-se por situações estressantes aquelas referidas, e então percebidas, pelas mães ao serem questionadas se haviam vivenciado situações estressantes ao longo do primeiro ano de vida do bebê.

\section{Método}

\section{Participantes}

Participaram deste estudo 39 mães com idade variando entre 20 e 37 anos $(M=28 ; d p=5,13)$, primíparas e que moravam com o pai do bebê na região metropolitana de Porto Alegre. A escolaridade média das mães era de 13 anos (dp=3,04). Os pais dos bebês tinham idade variando entre 20 e 50 anos $(M=31 ; d p=6,48)$ e escolaridade variando entre 4 e 20 anos $(M=12 ; d p=3,66)$. Em relação aos bebês, 20 (51\%) eram meninos e 19 (49\%), meninas. A amostra foi selecionada dentre os participantes do Estudo longitudinal de Porto Alegre: da gestação à escola ELPA (Piccinini, Lopes, Sperb \& Tudge, 1998) que teve por objetivo investigar tanto os aspectos subjetivos e comportamentais das interações iniciais pai-mãe-bebê como o impacto de fatores do desenvolvimento (ex. temperamento infantil, valores parentais, responsividade materna) nas interações familiares, no comportamento social de crianças préescolares e na transição para a escola de ensino fundamental. O ELPA iniciou acompanhando 81 gestantes que não apresentavam intercorrências clínicas, sejam com elas mesmas, sejam com o feto/bebê, que era seu primeiro filho. Os maridos ou companheiros também foram convidados a participar do estudo, caso residissem juntos, em situação matrimonial. Os participantes representavam várias configurações familiares (nucleares, monoparentais ou recasados), de diferentes idades (adultos e adolescentes) e com escolaridade e níveis socioeconômicos variado. No ELPA foram realizadas várias coletas de dados envolvendo a utilização de diversos instrumentos, desde a gestação até os sete anos das crianças (gestação, 3o, 8o, 12o, 18, 24, 30o meses e 6o, 7 o e $8^{\circ}$ ano de vida da criança). O convite inicial para participar do estudo ocorreu quando a gestante fazia pré-natal em hospitais da rede pública da cidade de Porto Alegre $(51,2 \%)$, nas unidades sanitárias de saúde do mesmo município (7,3\%), através de anúncio em veículos de comunicação $(26,8 \%)$ e por indicação $(14,6 \%)$. O estudo foi aprovado pelo Comitê de Ética da UFRGS - Universidade Federal do Rio Grande do Sul.

Afora os dados sociodemográficos coletados na gestação, os aspectos discutidos no presente artigo referem-se apenas aos dados do ELPA, obtidos na quarta fase de coletas de dados, ou seja, quando a criança contava 12 meses de idade. Detalhes das outras fases de coleta de dados e dos instrumentos utilizados podem ser encontradas em Piccinini e cols. (1998). Das 39 mães participantes do estudo, $22(56 \%)$ relataram ter enfrentado alguma situação estressante no período investigado.

\section{Procedimentos e instrumentos}

Após o contato inicial com as gestantes, nos diferentes locais de recrutamento, foi marcada uma visita no último trimestre de gestação, na residência da gestante, quando esta assinou o Consentimento Livre e Esclarecido e foi realizada a Entrevista de dados demográficos do casal (GIDEP, 1998). Quando o bebê completou 12 meses, as mães foram convidadas a virem na Universidade onde foi realizada a Entrevista sobre a Experiência da maternidade e o desenvolvimento do bebê aos 12 meses (GIDEP, 1998). Para fins do presente estudo destacaremos apenas as questões sobre os eventos estressantes e o apoio social dado à mãe ao longo do primeiro ano de vida do bebê, bem como os sentimentos das mães em relação a esse apoio social. A entrevista envolveu diversas questões sobre o desenvolvimento do bebê (ex.: Como está o desenvolvimento/crescimento do teu bebê?), sobre a maternidade (ex.: Como tu estás te sentindo como mãe? Que dificuldades tu tens sentido?) e eventos estressantes (Pensando um pouco nos cuidados do bebê ao longo do primeiro ano de vida, ao longo deste primeiro ano de vida, tu vivenciaste situações estressantes? Quais? Tu solicitavas mais ajuda nessas situações/períodos?). Os dados sobre eventos 
estressantes é que foram particularmente analisados neste artigo.

\section{Resultados}

Análise de conteúdo qualitativa (Bardin, 1977; Laville \& Dione, 1999) foi utilizada para se investigarem as situações estressantes envolvendo a maternidade e o apoio social recebido, que foram classificados em diversas categorias explicitadas a seguir. Durante análise dos dados, se priorizaram relatos que ilustrassem as diversas situações estressantes, independente de uma ser mais ou menos frequente do que outra, como é próprio das investigações qualitativas. A ideia subjacente a essa estratégia qualitativa de análise é se buscar entender o fenômeno sem destaque para eventuais diferenças na frequência com que as situações estressantes foram relatadas. Os resultados serão apresentados em duas sessões. Inicialmente serão destacados os eventos estressantes relatados pelas mães e, num segundo momento, o apoio social recebido durante essas situações ${ }^{2}$.

Situações estressantes se referem a eventos e situações percebidos pelas mães como lhes causando mal-estar físico ou emocional, envolvendo cansaço, preocupação, ansiedade, frustração, ambivalência ou medo. Os eventos considerados estressantes pelas mães foram classificados em dez categorias:

periodo pós-parto; amamentação; cansaço materno; insônia do bebế; cuidados iniciais; adoecimento do bebê; banho no bebê; desmame; aprendiragem do bebê; e, intromissão de avós.

A categoria aprendizagem do bebê necessita ser explicitada por ser inesperada ao referir-se a um bebê. Refere-se ao fato da mãe relatar que explica coisas para o bebê, mas sente que ele não aprende.

Apresenta-se a seguir a descrição de cada uma dessas categorias ilustrando-as com relatos das próprias mães. Como poderá ser visto, os relatos revelam uma interdependência entre os temas destacados, que não ocorriam isoladamente na vida real dessas mães e seus bebês. Dessa forma, para não segmentá-los demasiadamente, o que reduziria seu caráter explicativo, optou-se por mantê-los completos, mesmo quando envolvendo mais de uma categoria.

O período pós-parto foi considerado particularmente estressante em vários aspectos, referindo-se, primeiramente, o desconforto físico após

\footnotetext{
$2 \mathrm{Na}$ tese de doutorado, na qual se baseou este artigo, são apresentados outros relatos de situações estressantes e de apoio recebido, que não foram incluídos no presente artigo por razões de espaço. Em função disso, aqui também se buscou editar algumas citações, excluindo partes que não eram fundamentais para o seu entendimento.
}

o parto. Segundo uma das mães, o sofrimento materno ocorreu

Logo que ela nasceu, que foi um estresse total, porque eu ainda estava com os pontos. Ai ela não queria pegar o seio. Até nem pegou, ela mamou no leite mesmo.

Em outro depoimento uma mãe destacou que A chegada balançou bastante comigo no sentido de estar com um pouco de dor, de sentir muita dor no peito [...]. Nos primeiros dias, no sentido da dor, eu queria ter ficado um pouco mais próxima com ele e não fiquei. Então, eu acho que o que mais me marcou foi o fator da dor, de ainda estar um pouco cansada e ter que dar atenção para as pessoas que chegavam e dar atenção pra ele.

Outra mãe referiu sua falta de experiência como uma situação estressante:

Foi assim que ele nasceu, foi o primeiro mês. Até não digo o primeiro mês, os primeiros 20 dias [...], como en não sabia nada de bebê, ele chorava muito e eu achava que era a bendita cólica que o bebê tem, e na verdade, quando eu fui à consulta o médico disse: É fome. E eu não sabia e só dava mamá e o mamá não sustentava, eu tinha que dar complemento. Depois que eu comecei a dar acabou aquela choradeira, mas sem dúvida o inicio foi muito chato. O seio machucado, não gosto nem de lembrar, assim recém-nascido, a gente nem aproveitou bem ele, porque era só um cansaço, porque era noite e dia.

Como contraponto às dificuldades da amamentação, já mencionada no relato anterior, o desmame também foi citado como fonte de ansiedade e preocupações:

Foi desmamar ela, foi o mais difícil, porque ela não quis. Não queria, porque não queria. Tanto que ela não quis mais nem comer, mas de resto foi tranquilo [...7. Foi dificil, en chorei muito. Eu chorava, chorava, chorava [...] quando ela queria o peito e eu não pude dar o peito para ela e ofereci outra coisa e ela se debatia, ela tentava me bater e ela chorava e eu chorava junto. Com seis meses comecei a diminuir o mamá dela [...]. Ai tinha dias que eu entrava em desespero e diria: toma o mamá de uma vez filha, toma! Ai en dava mamá para ela, ai ela ficava calminha [...] $\dot{E}$ porque ela não tava comendo e ela diminuiu bastante o peso ela chegon a seis quilos.

Outro fator mencionado pelas mães foi o cansaço materno:

Porque criança é a coisa mais linda que tem e é um dom de Deus ser mãe. Só que ao mesmo tempo tu cansa, eu mesma, muitas vezes, vejo que eu preciso de umas férias. Eu precisava ficar um dia, dois, mas com uma pessoa que fosse junto e ficasse direto com a T., porque eu me sinto estressada, eu me sinto cansada. Porque mesmo que a criança seja boa, calma [...]. 
Porque o dia pra ti não tem 24, tem 48 horas, porque tu pode estar dormindo, mas tu está ali cuidando. Eu antes tinha um sono pesado, eu agora tenho um sono leve. Porque mesmo tu estando dormindo, qualquer chorinho tu levanta, então, tu não tens aquela noite direto só tua.

Em outro depoimento pode-se verificar também que o cansaço materno, associado tanto à falta de sono como à falta de ajuda paterna, pode levar a transtornos na própria relação conjugal:

Ele [pai] tinba que acordar de manbã cedo pra ir trabalhar, então, quem tinha que ficar acordando de noite para cuidar o L. era eu. Mas só que durante a manhã eu não conseguia dormir também, e aí continuava, depois de tarde en ia trabalhar normal. E aí à noite ele reclamava porque eu tava sempre reclamando que eu estava com sono. Ele dizia que não podia mais escutar en falar que en tava sempre com sono.

Conforme exposto na fala anterior, o cansaço materno apareceu particularmente associado às insônias do bebê:

Teve um periodo que ela comecon a acordar muito seguido de noite, com muito choro [...], ali foi bem puxadinho assim, porque ela comecon a sonbar $e$ acordar e eu não estava acostumada, porque ela nunca acordou de noite, mas nada de mais.

Outra mãe também destacou que

Uns dias ele mama de noite, isso estressa qualquer criatura, porque tu imagina tu te acordar de duas em duas horas, de uma em uma hora que, tem vezes que acontece [...] no outro dia tu estás um caco, tu não pode dormir e de manhã, porque cedo ele já está acordado, é um estresse total, tu não sabe o que acontece, porque já acorda, já está aquele estresse e ele ali na volta então tu perde a paciência, isso é difícil.

O banho do bebê também foi relatado como gerador de ansiedade devido à fragilidade e tamanho do bebê, usualmente associados ao medo de afogamento ou dano físico, como é exemplificado a seguir: "O primeiro banho dela que foi bem complicado para a gente começar a dar o banho, a gente tinha medo que ia deixar cair, e às vezes deixa cair mesmo".

Em outro caso, os cuidados iniciais foram muito difíceis para o casal, que relatou situações que indicavam a presença de sentimentos depressivos na mãe:

Os três primeiros meses são os meses que tu pensa: meu Deus, o que en fiz. da minha vida, será que en estava preparada, tudo en acho que passa na tua cabeça, en não quero estar aqui, como voltar atrás. O que en fiz. meu Deus, eu nunca mais vou dormir, nunca mais vou ter meu marido, nunca mais a gente vai sair [...]. Isso é assim, até conversando com outros casais, é um horror. $O$ [marido] diz: [...] "as pessoas têm medo de dizer como tu di₹, tão abertamente" [...]. Claro, a gente precisava mesmo de uma adaptação, foi muito difícil, mas passou, graças a Deus passou. O S. fala que en não me lembro do [filho] nos três primeiros meses: "Sim, porque foram tão horriveis que tu anulou". Mas eu me lembro, de situações como quando eu fiquei a primeira vez sozinha com o M. Foi horrivel, en fiquei pensando, meu Deus eu vou me matar, porque eu não sei o que en vou fazer, ele não parava, en já tinha tentado de tudo [...] Eu acho que os três primeiros meses foram todos de angústia, tinha as coisas do prazer, no momento que eu pensava, men Deus esse nenê que coisa mais linda, nasceu do amor de nós dois, como é que pode. [...] era muita angústia, e se ele chorar, e se ele regurgitar, men Deus ele tem refluxo e se ele se afogar, então a gente não dormia, dormia com a câmera em cima dele, dentro do nosso quarto, com a câmera ainda.

Uma situação muito mencionada pelas mães se relacionava ao adoecimento do bebê. O desamparo do bebê recém-nascido, aliado à falta de experiência materna, desencadeava o medo de que acontecesse algo com ele e tornavam estas situações muito estressantes:

Só quando ele teve essa bronquiolite aos quatro meses [...]. Foram duas noites, a última noite o [pai] ficon mais tempo acordado, porque na outra eu já tinha passado. Foram aquelas duas noites, que foi um verdadeiro inferno. Mas graças a Deus, só foram aquelas duas noites, foi angustiante, porque faltava o ar dele.

De acordo com outra mãe,

Todo o primeiro ano, teve o início que foi muito ruim, que a gente não sabia a doença que ele tinha, do refluxo, da alergia, então foi muito pesado, chegon a me impressionar, que en não achava que fosse ser tão pesado, e depois mais os dentes que incomodaram, ele ficou muito chato, mas agora está cada vez. melhor.

Episódios de gripe ou febre, no caso de um bebê recém-nascido também se constituíam em fonte de intensa ansiedade para as mães: "Quando ela tinha febre ou tava gripada, quando tava com febre alta e não baixava, isso me preocupava bastante e eu pensava um monte de coisas".

Em outra situação também estressante referese às limitações de compreensão e aprendizagem do bebê:

Estressante só é quando tu ensina, explica, fala, pensa várias vezes [...] Eu fiz letras, en tinha psicologia da educação, eu me lembro da minha professora, eu penso, por isso en acho que não tem teoria que te faça aguentar, é chato quando tu explica, ensina, mostra, explica de novo, ensina mostra, e aí não acontece nada, parece que não entra. É a parte que tira do sério. 
Por fim, a intromissão das avós na condução dos cuidados com o bebê também foi mencionada como uma situação estressante:

As avós se metiam muito, [...] Mais a avó paterna, a mãe dele. É, pra mim foi dificil, en fiquei bastante nervosa e o nenê sentia isso, ele via que eu não tava gostando. É, muito palpite.

Juntos esses relatos nos revelam diversas situações potencialmente estressantes experienciadas pelas mães do presente estudo. Eles nos permitem compreender que, além da complexidade da própria maternidade, situações estressantes pontuais ou contínuas ao longo do primeiro ano podem trazer muito desgaste físico e emocional para as mães, especialmente quando não recebem apoio de outras pessoas.

\section{Solicitação de apoio}

Em relação à solicitação de apoio durante as situações estressantes, as respostas das mães foram classificadas em quatro categorias: solicitava ajuda, solicitava informacões; pai ajudava; não tinha para quem pedir.

A análise dos relatos maternos mostra que durante as situações estressantes, havia uma maior solicitação de apoio. Essa solicitação era, muitas vezes, de ordem prática:

Tem que fazer nebulização, dai en tenho que me levantar de madrugada pra arrumar, ai eu tenho que chamar o [marido], pra ele cuidar dela, que ela fica muito chorona, eu tenho que pedir ajuda.

Outra mãe relatou:

Ele [marido] ajudou, mas a princípio ele queria ter deixado lá com a mãe dele. Eu disse pra ele que não, mas ele achou que en tivesse fingindo a [minha] indisposição. Eu disse não, dá uma olbada nele, eu só quero dar uma descansada [...]. Ele não sabia quando o F. tava com sede ou sentimento, ele não sabia como lidar com aquela situação.

Em outro caso:

Um dia eu liguei pra mãe chorando, mãe, por favor, vem me ajudar, eu não dou conta dele. Fui até o banheiro com o nenê no colo, eu chorava muito e eu não sei, em vez de largar ele na cama, que ele não se virava, $e$ ir fazer as coisas, não, ficava com ele no colo. E aquilo na cabeça, aquela agonia, embora en sempre quis muito ter ele, e a gravidez foi a melhor fase da minha vida [...] Mas depois que ele nasceu, foi muito diferente, aqueles primeiros tempos, en achei horrivel, tem a parte boa, lógico, o nenê, toda aquela coisa, mas na hora da choradeira, do cansaço, eu não dava conta. Eu nem comento, eu penso agora como é que pode. $O$ [marido] chegava, pegava ele para eu comer, eu não tinha nem comido, era muito choro, muita coisa, o coitadinho louco de fome e eu não sabia [...]. Embora a minha mãe tivesse a familia, ela ficou uns dias comigo, dai eu podia dormir um pouquinho.

A ajuda também podia ser informacional, quando a mãe solicitava informações:

Porque eu não tinha muito conhecimento. A minha mãe tem mais, ela já criou dois, deve saber melhor do que a gente o que fazer. Eu pedia pra ela, o que ela tem, será que é grave? Vamos levar pro médico? Precisa levar agora, de madrugada, será que não é melhor levar de manhã? Tentar abaixar a febre.

Algumas vezes para obter essa ajuda a mãe ligava para o pediatra:

Quando era em relação à saúde dela, en ligava pro pediatra [...] Porque en ligava todos dias quase, no início, todos dias, não, mas, assim, sempre quando tinha alguma coisa, en nem ligava pro consultório, en ligava pro celular.

Em alguns casos, o pai ajudava:

Quando via que eu estava me apertando, não conseguia fazer acalmar, ele ajudava, não precisava pedir. Ele me ajudou bem, ele ajudava, via quando estava complicado, ia e ajudava, então isso foi passando, foi passando, veio o frio depois, então aí ela continuou acordando um pouco de noite e com isso eu comecei a levar pra cama, azar, acordava também, mas nessas alturas, muito frio e a nenê acordando, en levava pra cama, podia ser frio, ser aconchego que ela queria. pedir ajuda:

Em outros casos, a mãe não tinha para quem

Nem sempre tem alguém. Como é que eu vou chegar e vou dizer "olha, tu poderia ficar com a [filha] agora, a tarde toda?" É difícil. Então, não. Nesta situação, en nunca peço, só quando eu estou fazendo algum servicgo, que eu preciso e que é perigoso ela estar por perto. Ou se é uma coisa rápida que eu tenho que fazer e ela está incomodando, então eu não posso, dai eu peço pra alguém.

\section{Discussão}

O puerpério e o primeiro ano de vida do bebê se constituem em um período bastante propício à ocorrência de crises, por causa das mudanças intra e interpessoais desencadeadas pelo parto e pelo nascimento e desenvolvimento do bebê (Brazelton \& Cramer, 1992; Maldonado, 1990; Stern, 1997; Winnicott, 1956). Nesse período de transição para a maternidade, onde inúmeras situações estressantes podem se fazer presentes, a mulher se torna mais sensível, angustiada e por vezes confusa, sendo comuns quadros de ansiedade e depressão, especialmente no caso do primeiro filho.

Os resultados do presente estudo revelam que, entre as principais situações geradoras de estresse 
ao longo do primeiro ano de vida do bebê, destacam-se o cansaço materno, a falta de sono e o fato de ter a vida regrada pelos horários e necessidades do bebê. Esses dados apoiam achados relatados na literatura (Peters, 1999), que mostram que uma das principais mudanças nos primeiros meses de vida do bebê referese à privação do sono e à adaptação da vida ao ritmo do bebê.

Além disso, inúmeras mudanças subjetivas, também podem gerar estresse, como as associadas aos diversos temas da constelação da maternidade (Stern, 1997) e que envolvem, por exemplo, a reorganização da identidade da mãe, bem como o relacionar-se com o bebe e sobre sua capacidade de manter o bebê vivo e crescendo. As mães passam de uma posição de serem cuidadas e protegidas durante a gravidez para serem cuidadoras. Associado a essas questões subjetivas maternas, pode-se também destacar o confronto entre o bebê real, com suas demandas e características e o bebê imaginado e idealizado durante a gestação (Lebovici, 1987).

Sentimentos contraditórios e ambivalentes, por parte das mães, são frequentes nesse período (Maldonado, 1990), como por exemplo: compaixão pelo bebê contraposta à raiva, por considerá-lo ingrato perante seus esforços, além da frustração diante de um bebê que lhe parece insaciável, exigindo muito e retribuindo pouco, privando-a de suas necessidades, tais como horas de sono e de repouso. Tal situação de insatisfação pode gerar sentimentos de culpa e inadequação por parte da mãe.

$\mathrm{Na}$ pesquisa realizada por Cavandish (2007), o número de horas de sono de muitas mães, nos quatro primeiros meses de vida do bebê, foi de três horas por noite, em média. Essa privação de sono trouxe problemas para a relação conjugal para metade das mães entrevistadas por Cavandish, que revelaram preferir dormir em lugar de fazer atividades com o marido. Por outro lado, esse mesmo estudo indicou que o pai conseguia dormir ininterruptamente por várias horas, pois eles geralmente não acordavam para atender o bebê. Independente de o bebê chorar, o estudo traz um fenômeno relativamente recente, que é o uso de babás eletrônicas e câmeras de vídeos no quarto do bebê. Esses equipamentos podem, em muitos casos, estar aumentando o nível de estresse das mães, que despertam com qualquer ruído.

Os resultados do presente estudo revelam ainda as situações de adoecimento do bebê, estando implícito, também, um medo de que acontecesse algo muito sério com ele. $\mathrm{O}$ cansaço e a própria depressão pós-parto (Miller, 1997), presente na fala de pelo menos uma das mães, que se referiu ao desejo de "se livrar do bebê", ou de outra, que queria "ter sua vida de volta", podem ser contrapostos à culpa por esses pensamentos, além do medo de ser punida com a perda do bebê, decorrente de uma doença, sufocamento ou até no banho. Talvez, por isso, assim como pela própria novidade da situação e fragilidade do bebê, o adoecimento tenha sido tão estressante. Além disso, a doença do bebê exige que os pais passem mais horas acordados, o que vem aumentar o seu cansaço. Além disso, as dúvidas da mãe sobre a sua capacidade de cuidá-lo são predominantes (Zimmermann e cols. 2001) e foram salientadas por Stern (1997) no tema vida e crescimento da constelação da maternidade. A questão central para a mãe logo após o nascimento do bebê é se terá condições de mantê-lo vivo e se poderá promover o seu desenvolvimento físico. Para Stern, isso explicaria o medo que não raras vezes as mulheres sentem de que o bebê pare de respirar, não se alimente adequadamente ou caia, sendo possível que se sinta inadequada nessa tarefa de cuidados. Por exemplo, no presente estudo, foram relatadas situações estressantes relacionadas à amamentação e ao desmame, que geravam ansiedade tanto em relação ao aspecto nutricional, como em relação ao desconforto físico da mãe quando o bebê não suga adequadamente o mamilo, o que pode levar a fissuras no seio, que, para Zimmermann e cols. (2001) muitas vezes são de origem psicogênica gerada por ansiedade.

O modo como as mulheres combinam o trabalho com a maternidade tem sido foco de estudos (Elliott, 2002). O retorno da mulher ao trabalho, pode gerar situações estressantes em muitas mães (Brazelton, 1994), podendo a continuidade da amamentação ficar comprometida pela necessidade de introdução de novos alimentos, além da aceitação por parte do bebê de que outra pessoa lhe dê o leite materno, depois de retirado e armazenado pela mãe. Como visto nos relatos do presente estudo, o desmame pode se configurar como uma situação estressante para algumas mães, pois ao perder o seu lugar de provedora que garante a sobrevivência do filho por meio do seu leite a mãe pode viver esse processo de separação de maneira sofrida. Como afirma Winnicott (1977), o desmame envolve um "processo gradual de demolição de ilusões" que se constitui em uma tarefa dos pais, sendo que o desejo de desmame deve partir das mães. Nessa mesma direção, a aquisição de habilidades pelo bebê, como engatinhar, caminhar, mexer em objetos, ao mesmo tempo em que tendem a ser bem-vindas para a mãe, pois estão associadas ao desenvolvimento e a uma maior autonomia, mas também podem gerar ansiedades e preocupações (Lopes e cols., 2007). Especialmente no final do primeiro ano de vida, a criança apresenta novas aquisições de linguagem, 
locomoção e exploração, que lhe permitem realizar movimentos de afastamento e reaproximação do cuidador, e a mãe precisa proporcionar oportunidades para descobertas e favorecer explorações. No estudo de Lopes e colegas, as mães relataram sentimentos ambivalentes, de gratificação e realização, mas também de maior demanda e dedicação.

Também relacionado às aquisições do bebê, chamou atenção no presente estudo o relato de mães sobre o estresse que tinham diante das limitações de compreensão e aprendizagem do seu filho. O fato de a mãe ter dificuldades de lidar com essa situação pode indicar, além de falta de conhecimentos sobre o desenvolvimento infantil, questões pessoais da mãe associadas a uma demasiada exigência e expectativa ante as quais o bebê não tem condições de corresponder. A mãe que é muito exigente com o bebê também o é consigo mesma em relação ao seu papel de mãe, e acaba nutrindo a expectativa de que ele seja ideal ou perfeito (Maldonado, 1990).

Apesar de muitas avós serem as principais provedoras de apoio social para a mãe, especialmente as avós maternas, por vezes sua intromissão com respeito aos cuidados e educação do neto apresenta-se como fator estressante para algumas mães. Também é comum a relutância das avós em aceitarem a crescente independência de seus próprios filhos, bem como a capacidade destes como pais, insistindo para que sigam seus conselhos. Tal fato exemplifica a situação paradoxal em que o apoio social é vivido, por vezes, como negativo, como foi relatado por algumas mães do presente estudo. Nessa direção, o estudo de Susin, Giugliani e Kummer (2005) revelou que as avós podem influenciar negativamente na amamentação, tanto na sua duração quanto na sua exclusividade, e que o contato não-diário com a avó materna foi fator de proteção para a manutenção da amamentação aos seis meses.

\section{Considerações finais}

Os relatos analisados no presente estudo mostram que as mães experimentam uma ampla gama de sentimentos ambivalentes em torno da experiência da maternidade. Se por um lado sentem-se muito felizes e apaixonadas por seus bebês, também é comum que se sintam extenuadas e ansiosas. Alguns dos sentimentos depressivos podiam ser decorrentes das experiências do período pós-parto, de situações revividas a partir do nascimento do bebê e/ou de características de personalidade destas mães. $\mathrm{Na}$ verdade, ao longo do primeiro ano de vida do bebê, tanto a mãe como o pai terão que realizar diversos tarefas de ajustamento psicológico (Zavaschi \&
Brunstein, 2001). Com destaque para a mãe, ela terá que passar pelo rompimento de uma fusão com o feto e das fantasias de completude e onipotência existentes na gravidez para uma situação de adaptação ao filho real que não corresponde ao imaginado. Por fim vai ter de manejar seus medos em lidar com o bebê frágil e aprender a tolerar e obter satisfação a partir das exigências de um bebê totalmente dependente dela.

Esses sentimentos, segundo Maldonado (1990), tendem a ser mais intensos quando há uma quebra muito grande da expectativa em relação ao bebê, a si própria como mãe e ao tipo de vida que se estabelece com a presença do filho, o que gera desapontamento, desânimo e sentimentos de impotência perante a nova situação. Assim, sintomas de depressão e apreensão diante da responsabilidade de cuidar de um bebê são bastante comuns, em graus variados, na grande maioria das puérperas, devido às novas demandas de adaptação características desse período da vida.

Como a maternidade não é tarefa fácil, o apoio social torna-se fundamental para o desempenho da tarefa materna. E aqui, cabe se perguntar o que acontece com as mães e seus bebês quando esse apoio não existe, ou é inadequado, como foi relatado por algumas participantes do presente estudo. A mãe é socialmente muito cobrada em relação aos cuidados do bebê e, em nossa cultura, fala-se em amor de mãe ou instinto materno como uma característica supostamente inata, que orienta a prática diária materna, que deve ser vista como gratificante, apesar das dificuldades. Badinter (1985) assinala que as mulheres sofrem preconceito quando não correspondem a esse modelo, e destaca que o instinto do amor materno é um mito decorrente de uma construção cultural e da idealização da experiência da maternidade.

Alguns relatos do presente estudo retrataram intensos sentimentos e dificuldades das mães, revelando uma face da experiência da maternidade que muitas não têm coragem de admitir. Muitas dessas mães, todas primíparas, falaram de seu desespero, de seu cansaço, do medo, da falta de paciência e de quanto seus maridos, mães e sogras ajudaram a passar por esses períodos difíceis. Embora o apoio eventualmente recebido não tenha anulado o efeito das experiências negativas, provavelmente o amenizou, possibilitando que grande parte das mães vivenciasse essa experiência de forma mais positiva, ao se sentirem apoiadas em suas tarefas práticas, bem como emocionalmente amparadas.

É importante destacar ainda, que alguns relatos parecem indicar a presença de depressão pós-parto, e não só de estresse decorrente das mudanças de vida, 
cansaço, etc. Schwengber e Piccinini (2004) confirmaram, em seu estudo, o impacto da depressão materna na interação mãe-bebê e destacaram a sua ocorrência inclusive no final do primeiro ano de vida, período em que foram realizadas as entrevistas do presente estudo. Segundo os autores, tem-se estudado as repercussões da depressão materna nos primeiros meses após o parto, sendo necessárias mais pesquisas a respeito de sua extensão e persistência ao longo do primeiro ano de vida do bebê.

Os resultados do presente estudo destacam a necessidade de apoio social para que as mães possam lidar adequadamente com a complexidade das situações que envolvem os cuidados do bebê. A participação dos familiares, amigos e de profissionais parece contribuir enormemente não só na resolução imediata de eventuais necessidades nos cuidados do bebê, mas propiciando à mãe a tranquilidade que precisa para cuidar do seu primeiro filho em todas as dimensões do cuidado físico e psicológico.

Embora muitas mães relatassem estarem satisfeitas com o apoio social recebido, cabe lembrar que as participantes deste estudo tinham, em sua grande maioria, escolaridade de nível superior e condições econômicas que lhes possibilitava inclusive a contratação de babás para situações em que os demais apoios sociais estavam ausentes. Seriam necessários novos estudos para estender essas conclusões para mães de escolaridade e nível socioeconómico baixos. Todavia, também as mães de nosso estudo, que gozavam de melhores condições sociais, relataram a dificuldade de receber um apoio social adequado, sentindo-se por vezes tão desamparadas quanto seu filho. Considerando que essas dificuldades não contribuem para o estabelecimento de uma boa relação mãe-bebê, salientamos a necessidade de se pensar em políticas públicas que avaliem cuidadosamente a situação das novas mães quando ainda estão no hospital - já que todas passam pelos hospitais buscando estabelecer eventuais trabalhos preventivos ou de intervenção para as díades mãe-bebê, que não podem contar com adequado apoio social ao retornarem para suas residências.

Enfim, os achados do presente estudo nos aproximaram das vivências de mães primíparas, cuja experiência é cercada de alegrias, mas também de dificuldades, num contínuo interjogo de sentimentos ambivalentes. Também consideramos fundamental que sejam desmistificadas algumas das ideias acerca da experiência da maternidade e do papel da mulher, tradicionalmente vistos somente nos seus aspectos positivos, o que inviabiliza um cuidado mais próximo da realidade. Esse papel vem sofrendo modificações nos últimos anos para atender a uma nova realidade de mulheres que trabalham fora, precisam ajudar economicamente a família e têm também outras ambições para a sua vida, além de ser mãe. Para atender a todas essas necessidades e anseios, é preciso uma maior participação do pai e de outras pessoas, além do apoio institucional, durante a gestação e os primeiros anos de vida da criança, cujas repercussões positivas serão sentidas pela mãe, pelo pai e, especialmente, pelo bebê.

\section{Referências}

Badinter, E. (1985). Um amor conquistado: O mito do amor materno. Rio de Janeiro: Nova Fronteira.

Bardin, L. (1977). Análise de conteúdo. São Paulo: Martins Fontes.

Brazelton, T. B. (1994). Momentos decisivos do desenvolvimento infantil. São Paulo, Martins Fontes.

Brazelton, T. \& Cramer, B. (1992). As primeiras relações. São Paulo: Martins Fontes.

Brito, R. C. \& Koller, S. H. (1999). Desenvolvimento humano e redes de apoio social e afetivo. Em A. M. Carvalho (Org.). O mundo social da criança: natureza e cultura em ação (pp. 115-129). São Paulo: Casa do Psicólogo.

Catafesta, F., Venturi, K. K., Zagonel, I. P. S. \& Martins, M. (2007). Pesquisa-cuidado de enfermagem na transição ao papel materno entre puérperas. Revista Eletrônica de Enfermagem [nternet]. 9(2). 457-75. Obtido em 16/10/2010 da world wide web: http://www.fen.ufg.br/revista/v9/n2/v9n2a13.ht m.

Cavandish, L. (2007). A crying shame. The guardian, London, September 14. Obtido em 02/03/2008 da world wide web: http://lifeandhealth.guardian.co.uk/wellbeing/sto ry/0,2169122,00.html.

Crockenberg, S. B. (1981). Infant irritability, mother responsiveness, and social support influences on the security of infant-mother attachment. Child Development 52, 857-865.

Crockenberg, S. \& McCluskey, K. (1986). Change in maternal behavior during the baby's first year of life. Child Development, 57, 746-753.

Dunkel-Schetter, C., Sagrestano, L. M., Feldman, P. \& Killingsworth, C. (1996). Social support and pregnancy: a compreensive rewiew focusing on ethnicity and culture. Em G. R. Pierce, B. Sarason \& I. G. Sarason (Orgs.). Handbook of social support 
and the family (pp. 375-412), Nova Iorque: Plenum Press.

Elliott, J. (2002). The value of event history techniques for understanding social process: modelling women's employment behaviour after motherhood. International Journal of Social Research Methodology, 5(2), 107-132.

Falceto, O. G. (2002). A influência de fatores psicossociais na interrupção precoce do aleitamento materno. (Tese de Doutorado). Porto Alegre: Universidade Federal do Rio Grande do Sul - Faculdade de Medicina. Programa de Pós-Graduação em Ciências Médicas: Clínica Médica.

Grupo de Interação Social, Desenvolvimento e Psicopatologia - GIDEP/UFRGS/CNPq (1998a). Entrevista de dados demográficos. Instrumento nãopublicado. Instituto de Psicologia. Universidade Federal do Rio Grande do Sul.

Grupo de Interação Social, Desenvolvimento e Psicopatologia - GIDEP/UFRGS/CNPq (1998b). Entrevista sobre a experiência da maternidade e $o$ desenvolvimento do bebê aos 12 meses. Instrumento não-publicado. Instituto de Psicologia. Universidade Federal do Rio Grande do Sul.

Laville, C.\& Dione, J. (1999). A construção do saber: Manual de metodologia da pesquisa em ciências humanas. Porto Alegre: Artes Médicas.

Lebovici, S. (1987). A mãe, o bebê e o psicanalista. Porto Alegre: Artes Médicas. (Original publicado em 1983).

Lopes, R. C. S., Oliveira, D., Vivian, A. G., Bohmgahren, L. M. C., Piccinini, C. A. \& Tudge, J. R. H. (2007). Sentimentos maternos frente ao desenvolvimento da criança aos 12 meses: convivendo com as novas aquisições infantis. Psicologia. Teoria e Pesquisa, BSB, 23, 5-16.

Maldonado, M. T. (1990). Psicologia da gravidez. $11^{\mathrm{a}} \mathrm{ed}$ Petrópolis: Vozes.

Miller, L. M. (1997). Postpartum mood disorders. Washington, DC: American Psychiatric Press, Inc.

Peters, J. K. (1999). Mães que trabalham fora: segredos para conciliar a vida profissional e familiar. São Paulo: Mandarim.

Piccinini, C. A. E., Lopes, R. C. S., Sperb, T. M. \& Tudge, J. (1998). Estudo longitudinal de Porto Alegre: da gestação à escola. Projeto de pesquisa não publicado, Instituto de Psicologia, UFRGS.

Pierce, G. R., Sarason, I. G., Sarason, B. R, Joseph, H. J. \& Henderson, C. A. (1996). Conceptualizing and assessing social support in the context of the family. Em G. R. Pierce, B. Sarason \& I. G. Sarason (Orgs.). Handbook of social support and the family (pp. 3-23). Nova Iorque: Plenum Press.

Rapoport, A. (2003). Da gestação ao primeiro ano de vida do bebê: apoio social e ingresso na creche. (Tese de Doutorado). Porto Alegre: Universidade Federal do Rio Grande do Sul - Faculdade de Psicologia. Programa de Pós-Graduação em Psicologia do Desenvolvimento.

Rowan, C., Bick, D. \& Bastos, M. H. (2007). Postnatal debriefing interventions to prevent maternal mental health problems after birth: exploring the gap between the evidence and UK policy and practice. Worldviews Evid Based Nurs; 4(2), 97-105.

Schwengber, D. D. S. \& Piccinini, C. A. (2004). Depressão materna e interação mãe-bebê no final do primeiro ano de vida. Psicologia: Teoria e Pesquisa, 20(3), 223-240.

Schwengber, D. D. S., Alfaya, C. \& Lopes, R. C. S. Piccinini, C. A. (2003). A orientação interacional como alternativa de intervenção precoce pais-bebê no contexto da depressão materna: algumas reflexões iniciais. PSICO (Porto Alegre), 34(2). 297-316.

Simons, R. L. \& Johnson, C. (1996). The impact of marital and social network support on quality of parenting. Em G. R. Pierce, B. R. Sarason \& I. J. Sarason. (Orgs.). Handbook of social support and the family (pp. 269-287). Nova Iorque: Plenum Press.

Stern, D. (1997). A constelação da maternidade. Porto Alegre: Artes Médicas.

Susin, L. R. O., Giugliani, E. R. J. \& Kummer, S. C., (2005). Influência das avós na prática do aleitamento materno, Revista de Saúde Pública; 39(2), 141-147.

Winnicott, D. W. (1956). Preocupação materna primária. Em D. W. Winnicott (Org.). Textos selecionados: da pediatria à psicanálise. Rio de Janeiro: F. Alves.

Winnicott, D. W. (1977). A criança e seu mundo. Rio de Janeiro: Zahar.

Zavaschi, M. L., Costa, F. \& Brunstein, C. O. (2001). Bebê e os pais. Em C. Eizirik, F. Kapczinski \& A. M. S. Bassols (Orgs.). O ciclo da vida bumana: uma perspectiva psicodinâmica (pp.41-57). Porto Alegre: Artmed.

Zimmermann, A., Zimmermann, H., Zimmermann,J., Tatsch, F. \& Santos, C. (2001). Gestação, parto e 
puerpério. Em C. Eizirik, F. Kapczinski \& A. M.

S. Bassols (Orgs.). O ciclo da vida humana: uma perspectiva psicodinâmica. (pp.29-39). Porto Alegre: Artmed.

Recebido em: 27/01/2010 Reformulado em: 10/10/2010 Aprovado em: 16/02/2011

Sobre os autores:

Andrea Rapoport é psicóloga (PUCRS), mestre e doutora em Psicologia do Desenvolvimento do Curso de PósGraduação em Psicologia do Desenvolvimento da Universidade Federal do Rio Grande do Sul, pesquisadora do CNPq e professora do Centro Universitário La Salle e Cesuca - Faculdade Inedi.

Cesar Augusto Piccinini possui doutorado e pós-doutorado na University College London (Inglaterra). É pesquisador do CNPq e professor do Curso de Pós-Graduação em Psicologia da Universidade Federal do Rio Grande do Sul. 